\title{
Impact of comic factor in tv ads on buying behavior of university students
}

\author{
Qamar Farooq ${ }^{1 *}$, Nouman Shafique ${ }^{1}$, Muhammad Mahboob Khurshid ${ }^{2}$, \\ Naveed Ahmad ${ }^{3}$ \\ ${ }^{1}$ Scholar Preston University Islamabad, Pakistan \\ 2MS Scholar, COMSATS Institute of Information Technology, Islamabad, Pakistan \\ ${ }^{3}$ Department of Business Administration, Lahore Leads University, Pakistan \\ *E-mail address: f4farooq@gmail.com¹ shafique.nouman@gmail.com \\ mmk2000_pk@yahoo.com² naveeddgk2010@gmail.com³
}

\begin{abstract}
This study was carried out to find out the impacts of comic factor in TV advertisement on buying behavior of college and university students. Questionnaire was designed and used to gauge the effects of comedy in advertisements. Sample size was 120 and it was comprised of university business students (Preston University Islamabad, International Islamic University Islamabad and Qauid-e-Azam University Islamabad). Data Analysis provided coefficient of determination R square value as 0.576 . With significant Alpha figure of all variables, $\mathrm{F}$ value was 26.907 at 0.01 level. Outcomes revealed that comedy in TV advertisement convinces the consumer's attention, interest, desire and action (AIDA) to buy the product. Objective of the study was achieved as it was found out that comic factor in TV ads affect the attention, interest, desire and action and hence buying behavior of students. Results also revealed that buying behavior of students due to comic factor in TV ads is gender free.
\end{abstract}

Keywords: Comic factor; TV Ads; Consumer Buying Behavior

\section{INTRODUCTION}

\section{Backgound}

Advertising is approximately everywhere in our everyday living. Its shapes and roles are equally well liked. Advertisements add new sounds and the marks which form feature; its language and descriptions represent the present and the history. Some perceive advertising like the mirror and the architect of culture. Others believe advertising as simply an economic movement with single intention that is to sell. Most of the advertisers and groups say that advertising produces "magic in the market place" (Russell, 1996). Advertisement has altered its shape from town criers of medieval time to the electronic advertisement and internet (David, 2001).

\section{Problem Statement}

Every human society extends a system through which people provides and distributes goods and services. All those efforts, which are carried out to craft an advertisement effective, 
efficient and persuasive, mechanism on a sole dictum to meet the consumer mind in an optimistic way. In advanced societies of current era, as the development proceeds on this system become very composite because of extensive range of on hand options. To comprehend this system completely what is required is the learning of a person's entire life familiarities and experiences about utilization of economic goods as it prevails approximately each activity wherein humans are concerned. Now in this view point, consumer behavior seems to be subset of human behavior for the aspects, which affect people in their routine lives and influence their buying actions, hence, understanding regarding influence of important features involved to sway buying behavior of consumers, is essential. Hence, in order to make the develop understanding about one of the important factors, following research questions have to be answered:

1. Does comic factor in TV ads positively affect the Student's behavior to buy a product/service?

2. Does comedy in advertisements affect differently on both genders?

\section{Research Objectives}

1. To ascertain the impact of comic factor in TV ads on purchasing behavior of College and University students

2. To find out the impact of comic factor in ads on male and female students

\section{Significance of Study}

This study has been carried out to determine the impact of comic factor in advertisement on consumers' behavior in reference to TV ads and their effects were checked. The main concept of this study was to check whether comic factor in TV ads affect the attention, interest, desire and action for purchasing the product. Because TV ads cost much as compared to other means of advertisements, so due attention has to be paid in order to make these ads maximally effective. The study provides an adequate guideline for the regulator, advertisers and media simultaneously for reformulation of their strategies in the view of the prevailing drift with the vision of making television ads more effectual.

\section{LITERATURE REVIEW}

Researchers and scholars are agreed on these six basic principles on which advertising movement works: to secure attention; to arise interest; to develop and sustain that interest; creating desire; to incite action and to create good will (Shahid, 1999). Having selected an apt strategy and decision of the marketing objectives, media selection is the next significant contemplation which is the major vehicle that is used for the delivering of the message. Few important tools of advertisement are direct mail and mail order, magazines, newspapers, radio, television, outdoor display and transport (Wells, Burnett \& Moriarty, 2000).

The method founded on "hierarchy of effects" proposes that there are informal associations between variations in person's attitude for a product and person's attitude to purchase that very product. The models of advertising propose that for effectiveness, any piece of influential message must carry its viewers through a chain of stages, each stage being dependent on the achievement of every previous phase (Wilmshurst, 1985; Lavidge \& Steiner, 1961; Leckenby, 1976; Colley, 1961). 
Advertisement convinces the consumer to buy the product at least once in a life. Personality used in ads influenced the customers more as compared to keyword or caption. Moreover, consumers considered advertisement as an unswerving source of knowledge as compared to others (neighbors, friends or reference groups) opinions. Advertisement can shape any income group, but costly good and recurrence of advertisement did not influence the buying attitude (Aneeza \& Najma, 2009).

There are different types of humor and different products that are more or less apposite for television advertising. There are some big benefits of using humor in television advertising, but there are some deliberations that have to be addressed (Olsson, 2005). Internal influences like society, family, social class, reference group, culture and opinion leaders also affect us in our functions as a consumer (Loudon \& Bitta, 1994; Foxall \& Goldsmith, 1994; Ralphs, 1993). Wilkie (1994) delineated consumer behavior as "the mental, emotional, and physical activities that people engage in when selecting, purchasing, using, and disposing of products and services so as to satisfy needs and desires".

Normative influences of Pakistani University Students, buoyancy, Perceived Quality, Emotional Value \& Brand Consciousness are direct and Indirect Factors of Purchase Intention. Also Brand consciousness has significant impact on Emotions. Normative Influence has positive impact on purchase intention throughout brand consciousness, supposed quality and emotions (Nasir, 2010).

Humor raises ad information recall and has positive affect on brand attitude. Because of its potential use, humor and its role in commercial advertising will remain the concern of researchers and practitioners identically. Perceived humor seems to be influenced by societal setting, but uninfluenced by another mediating factor: the occurrence of exposure (Zhang \& Zinkhan, 1991). On the other side, regarding internationalization context, Mooij (1994) reported that humor is heavily cultural-bound.

Success of humor as an advertising tactic is based on the aspect that humor makes consumers to watch, laugh and remember. The latter aspect carry massive weight as in recall tests, consumers most often remember humorous ads. For Success, humor should be connect to product advantages and should ties the product features, benefits to the consumers and personal values of the mean-ends (Clow \& Baack, 2002)

\section{THEORETICAL FRAMEWORK}

The starting point of construct was identification of ways that influence the human mind process and this understanding is essential to be able to recognize what activities are needed to convince consumers to buy products. This is done in cognitive psychology, which studies the mind processes, which motivate thinking, logic and decision-making. Naming only a few aspects, cognitive psychology covers reminiscence, attention, perception and knowledge demonstration. The mind processes form the basis for a phased approach that is largely used in advertising and marketing. Concerning the consumer awareness of products, the AIDA approach is a well-recognized concept. This was formerly formulated in the early 20th century. AIDA plunks for the different phases a customer goes through before she or he buys a good:

Attention: attracting the attention of a customer

Interest: raising customer interest by demonstrating features and benefits

Desire: convincing customers that the good will satisfies their needs

Action: stimulating customers to buy a good

All stages are uniformly important and need to be satisfied. The standard AIDA hierarchical model is demonstrated as below: 


\section{ATTENTION}

INTEREST

DESIRE

ACTION
- Grab their Attention

- Build their Interest

- Create the Desire

- Persuade them to take Action

Seeing the impact of comic factor in TV ads on the attention, interest, desire and action of the consumer:

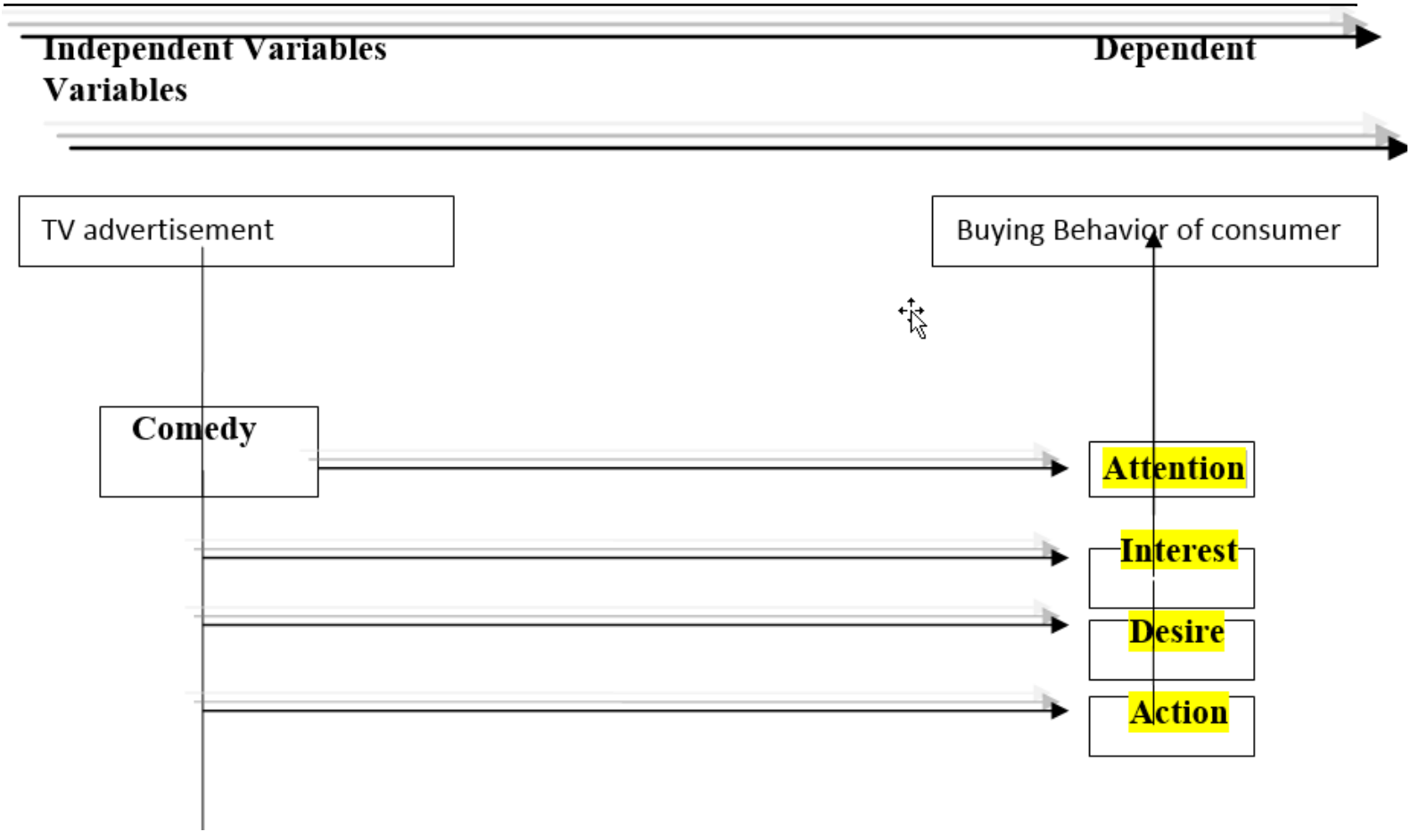

\section{Hypotheses}

H1: Comic Factor in TV ads positively affects the consumer buying behavior

H2: Impact of comic factor in advertisements is gender free 


\section{METHODOLOGY}

Students were selected from three main universities of Islamabad (Quaid-i-Azam University, International Islamic University and Preston University). Business students were taken as convenience sampling (60 Males and 60 Females). Response rate was good because out of 120, 100 (50 Males and 50 Females) responses were received from respondents. Data was collected through questionnaire (Using Likert Scale ranging from 1 to 5), which was based on the variables i.e. Comedy, attention, interest, desire and action and 3 questions for each variable were built in the questionnaire. Collected data was organized, summarized and analyzed through descriptive statistics by finding correlation and regression through the statistical software "Statistical Package for Social Sciences" (SPSS).

\section{RESULTS AND DATA ANALYSIS}

\section{Consistency and Reliability}

Reliability effect of Comic factor in TV ads on consumer buying behavior is measured in this study. To check the consistency and reliability, the instrument Cronbach's Alpha was calculated using SPSS (Statistical Package for Social Sciences).

Table 1. Consistency and Reliability.

\begin{tabular}{ccc}
\hline Variable & Cronbach's Alpha & N of items \\
\hline Comedy & .731 & 3 \\
Attention & .791 & 3 \\
Interest & .894 & 3 \\
Desire & .873 & 3 \\
Action & .785 & 3 \\
\hline
\end{tabular}

Cronbach's Alpha for five variables TV Ads, Attention, Interest, Desire, and Action was $.731, .791, .894, .873$ and .785 respectively and was also in acceptable range. Cronbach's Alpha indicates that consistency and reliability of measures used in this study could be considered as good as shown in above tables.

Table 2. Correlation between Elements of Dependent Variables and Independent Variable. Using SPSS, Correlations among all variable were found, and result is presented in tabulated form as.

\begin{tabular}{cccccc}
\hline & TV Ads & Attention & Interest & Desire & Action \\
\hline TV Ads & 1 & & & & \\
Attention & $.364^{* *}$ & 1 & & & \\
Interest & $.249^{*}$ & $.233^{*}$ & 1 & & \\
Desire & $.272^{* *}$ & $.226^{*}$ & $.932^{* *}$ & 1 & \\
Action & $.330^{* *}$ & $.873^{* *}$ & $.393^{* *}$ & $.426^{* *}$ & 1 \\
\cline { 2 - 6 }
\end{tabular}

**. Correlation is significant at the 0.01 level (2-tailed). 


\begin{tabular}{cccccc}
\hline & TV Ads & Attention & Interest & Desire & Action \\
\hline TV Ads & 1 & & & & \\
Attention & $.364^{* *}$ & 1 & & & \\
Interest & $.249^{*}$ & $.233^{*}$ & 1 & & \\
Desire & $.272^{* *}$ & $.226^{*}$ & $.932^{* *}$ & 1 & \\
Action & $.330^{* *}$ & $.873^{* *}$ & $.393^{* *}$ & $.426^{* *}$ & 1 \\
\cline { 2 - 6 }
\end{tabular}

**. Correlation is significant at the 0.01 level (2-tailed).

*. Correlation is significant at the 0.05 level (2-tailed).

Methodological analysis of the results shows a positive correlation between Comedy and Attention $(r=0.364)$, Comedy and Interest $(r=0.249)$, Comedy and Desire $(r=0.272)$, Comedy and Action (0.330) is significant at 0.01 and 0.05 level. This correlation shows that Comic factor in TV ads has significant effect on Consumer Buying Behavior (AIDA) and there is strong degree of association between variables in the model.

Overall response for each variable has been analyzed and mean and SD (standard deviation) values are shown in table03 as under:

Table 3. Comparing Means of Variables.

\begin{tabular}{ccccc}
\hline Factors & Gender & Mean & N & Std. Deviation \\
\hline Comic Factor & Male & 4.4467 & 50 & .26607 \\
& Female & 4.2333 & 50 & .75668 \\
Attention & Total & 4.3400 & 100 & .57439 \\
& Male & 4.5800 & 50 & .28420 \\
& Female & 4.3267 & 50 & .79537 \\
Interest & Total & 4.4533 & 100 & .60769 \\
& Male & 4.3800 & 50 & .85717 \\
& Female & 4.3400 & 50 & .79821 \\
Desire & Total & 4.3600 & 100 & .82427 \\
& Male & 4.4400 & 50 & .70772 \\
& Female & 4.3400 & 50 & .79821 \\
& Total & 4.3900 & 100 & .75218 \\
& Male & 4.5622 & 50 & .29131 \\
Mean of Variables & Female & 4.2489 & 50 & .76506 \\
& Total & 4.4056 & 100 & .59707 \\
& Male & 4.4906 & 50 & .43994 \\
& Female & 4.3139 & 50 & .64648 \\
& Total & 4.4022 & 100 & .55726 \\
\cline { 2 - 4 } & & &
\end{tabular}

Comparison of means show that the mean values for all variables for both males and females is very close and it can be stated that males and females both have same responses for all variables and comic factor in TV ads have same effect on both genders. The overall response according to gender is summarized in all above tables for males and females. 
Table 4. Regression results of the model.

After performing various tests, the figures obtained have been presented in Table 04,05 and 06.

Regression for Leadership Styles and Project Success.

\begin{tabular}{ccccc}
\hline Model & $\mathrm{R}^{2}$ & $\Delta \mathrm{R}^{2}$ & $\mathrm{~F}$ & Sig. \\
\hline TV Ads & .576 & .576 & 26.907 & .001 \\
\hline
\end{tabular}

Dependent Variable: Buying Behavior

The coefficient of determination R. square is 0.576 . And, this provides us the ratio of explained variation to total variation. By converting the $\mathrm{R}$. square value to percentage it comes to be around $58 \%$. Meanwhile, from this percentage it is concluded that 58 percent of the variability of Dependent variables have been explained by the variation of Independent variable in this model. $\mathrm{F}=26.907$ is statistically highly significant at 0.01 level, indicating that the independent variable totally is statistically significant, and is giving model a good fit.

\section{DISCUSSION}

Television commercials usually come immediately to mind when one mentions "advertisement". AIDA model is an authentic and already proved model. The present study has been conducted to find out the effects of advertisement on consumer buying behavior of College and University students. Analysis of the data revealed that comic factor in TV advertisement convinced the students to purchase the product. It can be further said that advertising through TV after adding comic factor is an effective way in order to add value in product and attract the attention of a customer (attention), raising customer interest by demonstrating features and benefits (interest) and to encourage customers that the product/service will satisfy their needs (desire) and stimulate customers to buy a good (action). This study is supportive of AIDA model which shows the relation of Attention, Interest, Desire and Action with Consumer buying behavior. In addition, the study worked on lines of perception that humorous ads lean to produce higher levels of perceived humor, positive action attitude, and brand information evoke. Based on the sample, TV ads containing comic factor have more influenced power than serious ads possibly through a mediating process of AIDA. Moreover, comedy is perceived to important element for TV ads. The findings here also indicated about the male and female inclinations towards getting inspiration from TV ads having comic factor included.

\section{CONCLUSION}

Considering the findings of the study it can be concluded that Comic factor in TV ads has positive impact on the consumer buying behavior of University students. Effect of comic factor in TV ads on both genders is same which means that attention, interest, desire and action are affected with almost same extent for both genders hence impact of comedy is gender free. Our Hypotheses $\mathrm{H} 1$ and $\mathrm{H} 2$ both have been accepted. 


\section{Recommendations}

Regulators, advertisers and media should reformulate strategies to consider comedy an important factor for making TV ads more effective regarding college university students' utilities.

The products under consumption of both genders (male and/or female) university students (e.g., Jeans, Laptops, meals, transports etc.) should be advertised through TV after incorporating comic factor for putting significant impact on consumers.

\section{Limitations of Study}

Followings are some limitations of the study:

$\checkmark$ The sample size was not sufficiently diverse to give the representation of all consumers, and because data was collected only from three universities of Islamabad, Quaid-i-Azam University, Preston University, International Islamic University so it would not be safe to generalize it to the all the University students of Pakistan.

$\checkmark$ Students from Islamabad only were taken as population, which is not enough for measuring detailed impact of comic factor in TV ads on consumer buying behavior.

$\checkmark$ Only Comic factor has been taken in TV ads while for finding detailed insight different styles/themes of TV ads could be included.

\section{Directions for future research}

This research study was simple one employing only consumer buying behavior of students. In future to find the effect of TV Ads on consumer buying behavior some complex models including other factors like styles/themes (i.e. Jingle, class, culture and modernity level etc). The social aspect of humor appreciation has sufficient room for supplementary study.

\section{References}

[1] Bashir, A., Malik, Najma I., (2009), Effects of Advertisement on Consumer Behavior of University Students, Proceedings $2^{\text {nd }}$ CBRC, Lahore, Pakistan.

[2] Clow, K.E. \& Baack, D. (2002), Integrated Advertising, Promotion and Marketing Communications, Prentic Hall, New Jersey.

[3] Colley, R. (1961), Defining Advertising Goals for Measured Advertising Results, Association of National Advertisers, New York.

[4] David, J. (2001), Effects of Television Advertising on Child's Purchase Behavior, National Institute of Psychology, Quaid-Azam University, Islamabad.

[5] Jakstien, S., Susnien, D., Narbutas, V. (2008), The Psychological Impact of Advertising on the Customer Behavior, Communications of the IBIMA, Vol 3.

[6] Lavidge, R. C., \& Steiner, G. A. (1961), A Model of Predictive Measurement of Advertising Effectiveness, Journal of Marketing, 59-62.

[7] Leckeny, J. D. (1976), Conceptual Foundations for Copytesting Research, Advertising Working Papers no. 2, Unknown Publishers, USA.

[8] Miles, M.B. \& Huberman, M.A. (1994), Quantitative Data Analysis, Second Edition. 
[9] Olsson, V., Lasson, A. (2005). Humor in Advertising: LuleÃ¥ tekniska universitet.

[10] Shaheen, N. (2010) Purchasing Behaviour: Journal of Managerial Scineces (Vol II)

[11] Russell, J. T., \& Lane, W. R. (1996), Advertising Procedure, 13th Ed., Prentice Hall Inc. USA.

[12] Strong, Jr. E.K. (1925), Theories of Selling, Journal of Applied Psychology, vol 9, issue 1, pp. 75-86.

[13] Tellis, G. J. (1987). Advertising exposure, loyalty, and brand purchase: a two-stage model of choice.

[14] Tellis, G. J. (2004). Effective advertising understanding when, how and why advertising works. California: Sage Publishers.

[15] Wells, W., Burnett, J., \& Moriarty, S. (1995). Advertising principles and practice (3rd ed.). USA: Prentice Hall.

[16] Wells, W., Burnett, J., \& Moriarty, S. (2000). Advertising principles and practice (5th ed.). USA: Prentice Hall.

[17] Wilkie, W. L. (1994). Consumer behavior (3rd ed.). USA: John Wiley \& Sons, Inc.

[18] Wilmshurst, J. (1985). The fundamentals of advertising. Singapore: Butterworth Heinemann.

[19] Wilmshurst, J. (1995). The fundamentals of advertising (2nd ed.). Singapore: Butterworth Heinemann.

[20] Wright, S. J., Warner, S. D., \& Winter, L. W. (1971). Advertising (3rd ed.). New York: McGraw-Hill.

[21] Zhang, Y., Zhinkhan, M.G. (1991). Humor in Television Advertisement: Advances in Consumer Research. Houston. Pp. 813-818. 